\title{
Erosion and abrasion-inhibiting in situ effect of the Euclea natalensis plant of African regions
}

\section{Silvia Helena de Carvalho SALES-PERES(a) \\ Cheila Nilza Hamina XAVIER(a) \\ Marta Artemisa Abel MAPENGO(a) \\ Moacir Rossi FORIM(b) \\ Maria de Fatima SILVA(b) \\ Arsenio SALES-PERES(a)}

(a) Universidade de São Paulo - USP, Bauru School of Dentistry, Department of Pediatric Dentistry, Orthodontics and Public Health, Bauru, SP, Brazil.

(b) Universidade Federal de São Carlos - UFSCAR, Department of Chemistry, Laboratory of Natural Products, São Carlos, SP, Brazil.

Declaration of Interests: The authors certify that they have no commercial or associative interest that represents a conflict of interest in connection with the manuscript.

Corresponding Author:

Sílvia Helena de Carvalho Sales-Peres

E-mail:shcperes@usp.br

DOI: 10.1590/1807-3107BOR-2016.vol30.0085

Submitted: Aug 11, 2015

Accepted for publication: Feb 05, 2016

Last revision: May 10, 2016
Abstract: This study evaluated the effect of Euclea natalensis gel on the reduction of erosive wear with or without abrasion, in enamel and dentin. During two five-day experimental crossover phases, volunteers $(\mathrm{n}=10)$ wore palatal devices containing human enamel and dentin blocks $(E=8$ and $D=8)$. The gel was applied in a thin layer in the experimental group, and was not applied in the control group. In the intraoral phase, volunteers used the palatal appliance for $12 \mathrm{~h}$ before the gel treatment, and were instructed to start the erosive challenges $6 \mathrm{~h}$ after the gel application. Erosion was performed with Coca-Cola ${ }^{\circledR}$ (for $5 \mathrm{~min}$ ) 4 times/day. The appliance was then put back into the mouth and was brushed after 30 minutes. After intraoral exposure, the appliances were removed and the specimens were analyzed using profilometry (mean $\pm S D, \mu \mathrm{m}$ ). The Euclea natalensis gel caused less wear in enamel in the experimental group (EROS $=12.86 \pm 1.75 \mu \mathrm{m}$; EROS + $\mathrm{ABRAS}=12.13 \pm 2.12 \mu \mathrm{m})$ than in the control group $(\mathrm{EROS}=14.12 \pm 7.66 \mu \mathrm{m}$; EROS + ABRAS = $16.29 \pm 10.72 \mu \mathrm{m})$; however, the groups did not differ from each other significantly. A statistically significant value was found for erosion and eros + abrasion in dentin $(\mathrm{p}=0.001)$. Euclea natalensis may play a role in the prevention of dentin loss under mild erosive and abrasive conditions. A clinical trial is required to confirm these promising results in a clinical situation.

Keywords: Tooth Wear; Tooth Erosion; Tooth Abrasion; Disease Prevention; Ebenaceae.

\section{Introduction}

Dental wear is a known multifactorial condition that may represent an association of erosion, abrasion, attrition and abfraction. Acidic foods are consumed worldwide; ${ }^{1}$ however, their effects on the mouth are universally assumed to be harmless. Acidic beverages and foods can affect natural teeth, and chronic exposure often leads to the development of dental wear. ${ }^{2}$ The most recognized cause of abrasion is brushing, in which not only the type of toothpaste and brush are responsible, but poor technique and excessive brushing force (after acid challenge) may also act as aggravating factors.

Erosive and abrasive processes are frequently observed, and are often associated, because abrasion of the dental hard tissue is considerably aggravated by exposure to acids (erosion). ${ }^{3}$ Efforts have been made to elucidate how erosive/abrasive lesions may be prevented. ${ }^{4}$ 
Several strategies have been used to prevent dental erosion and/or abrasion, such as topical application of fluoride or calcium-phosphate formulations. ${ }^{5}$ Another option is the addition of calcium, phosphate, iron, ferrous sulphate, ${ }^{4}$ titanium tetrafluoride, ${ }^{6}$ and/or sodium hexametaphosphate to rinsing solutions or toothpastes.7 Similarly, investigations into the contribution of natural products, such as propolis, ${ }^{8}$ neem ${ }^{9}$ and green tea, ${ }^{10}$ have been used in experimental formulations for the treatment of different oral diseases. ${ }^{8,9}$

Herbs with medicinal properties are a useful and effective source of treatment for various disease processes. ${ }^{11}$ The Euclea natalensis plant has been used for oral hygiene, and also for treating some respiratory diseases in Africa, notably by the indigenous population of South Africa. ${ }^{12}$ The root bark is removed and the inside is chewed until it breaks up; afterwards, it is rubbed against the teeth and gums. The root of the Euclea natalensis is used to clean the teeth in certain regions of Africa. ${ }^{12,13}$ Fresh root samples of Euclea natalensis were tested against Streptococcus mutans, human saliva and periodontal pocket isolates, and it was found that both aerobic and anaerobic bacterial growth (Porphyromonas gingivalis, Prevotella intermedia and Treponema denticola) was suppressed in all instances. ${ }^{13,14}$ These plant extracts showed moderate cytotoxicity on the Vero cell line. ${ }^{14}$

Studies have demonstrated that the polyphenols contained in certain natural products, such as propolis ${ }^{8}$ and green tea, ${ }^{10,15}$ may have inhibitory properties against matrix metalloproteinases (MMP) -2 and -9, which could affect the remineralization of artificially demineralized dentin. ${ }^{10,15}$ The roots of the Euclea species are rich in naphthoquinones, which may help explain their therapeutic activity, since these compounds have fungicidal, antibacterial, insecticidal, phytotoxic, cytotoxic and anti-carcinogenic properties. ${ }^{14}$ These naphthoquinones may also have properties that protect against enamel and dentin demineralization, thus inhibiting metalloproteinases..$^{14,15}$

In a previous in vitro study, Euclea natalensis promoted the reduction of dentin demineralization caused by acids, thus showing that this plant was effective in inhibiting dentin dissolution. However, an in situ evaluation of Euclea natalensis has not yet been conducted to determine the reduction of enamel and dentin demineralization, in situations of high levels of acid challenge. Thus, the aim of this in situ study was to investigate the effect of Euclea natalensis gel on the erosive wear of enamel and dentin.

\section{Methodology}

\section{Ethical aspects and subjects}

This research was approved by the Research Ethics Committee of the Bauru School of Dentistry, University of São Paulo (Protocol no. 010/2011). The study was conducted in full accordance with the Declaration of Helsinki. For subjects to be included in the study, they had to provide a written informed consent, be age 18 to 40 years, be in good health with no evidence of communicable diseases, have a stimulated whole saliva flow rate of $1.0 \mathrm{~mL} / \mathrm{min}$, and no evidence of active caries or periodontal disease. The exclusion criteria included presenting any medical condition that could be expected to interfere with the safety of the volunteer during the study period, being a smoker, having received topical application of agents with high fluoride concentration at least 2 weeks prior to the beginning of the study, and presenting systemic diseases such as xerostomia and gastro-esophagic disorders. ${ }^{4,16}$

The sample size was calculated based on the data from a pilot study on surface microhardness change. A sample size of 4 volunteers was necessary to provide an a-error of $5 \%$ and a power of $80 \%$ and a relevant difference of $10 \%$ between gel and control groups. Ten volunteers were included in each group, because the variability could be higher for cross-sectional hardness, and because of possible losses inherent to in situ studies. ${ }^{17}$ The ten healthy volunteers lived in the same fluoridated $(0.70 \mathrm{mg} \mathrm{F} / \mathrm{L})$ area, presented adequate, stimulated salivary flow, and wore acrylic palatal appliances.

Stimulated saliva was collected by chewing a piece of rubber band for $5 \mathrm{~min}$ and spitting out every 1 minutes. ${ }^{4}$ Volunteers with a salivary flow under $1 \mathrm{~mL} / \mathrm{min}$ were not included in the sample. The volunteers' mean salivary flow was $1.34 \pm 1.12 \mathrm{~mL} /$ minutes.

\section{Experimental design}

This randomized in situ study was a single-blind trial conducted in two phases based on Sales-Peres et al., ${ }^{4}$ designed to compare the effect of Euclea natalensis gel 
on enamel and dentine erosive wear. Ten subjects who met the inclusion criteria, as cited before, attended two phases of 5 days each, with a washout period of 7 days and in situ/ex vivo erosion. The volunteers wore acrylic palatal appliances each containing four enamel specimens and four dentin specimens of human teeth, randomly assigned to two rows and four columns. The specimens in the first row were submitted only to erosion, and those in the second row, to erosion plus abrasion.

The factor under evaluation was treatment for dental erosion and dental erosion plus dental abrasion on two levels: non gel treatment (control group - CG) and treatment with Euclea natalensis (experimental group - EG), and dental substrate treatment on two levels: human enamel and dentin (subgroups E and D, respectively), ${ }^{4,17}$ The sequence of treatments was designed to make the in situ protocol easier to be followed by the volunteers. In the first phase, the specimens were subjected to gel treatment (EG); in the second phase, the specimens were not subjected to gel treatment (CG). The phases were also randomized. Half of the volunteers started the study in the first phase, and the other half, in the second phase. After the end of each phase, the volunteers crossed over to the other phase.

\section{Sample preparation}

The enamel and dentin specimens $(4 \times 4 \times 3 \mathrm{~mm})$ were prepared from freshly extracted impacted human third molars, stored in an aqueous $0.1 \%$ thymol solution for 30 days. All tooth surfaces were used for preparation of the specimens (crown and root for the enamel and dentin, respectively). The enamel surface of the slabs was ground flat with water-cooled carborundum discs $\left(320,600\right.$ and 1200 grades of $\mathrm{Al}_{2} \mathrm{O}_{3}$ papers; Buehler, Lake Bluff, USA), and polished with diamond spray (1 $\mathrm{mm}$; Buehler). The same procedure was used for the dentin surfaces, except for the 320 grade $\mathrm{Al}_{2} \mathrm{O}_{3}$ papers. ${ }^{4}$

Surface Knoop microhardness tests were performed (Knoop diamond, $50 \mathrm{~g}$, $10 \mathrm{~s}$ for enamel and $25 \mathrm{~g}, 5 \mathrm{~s}$ for dentin; HMV-2000; Shimadzu Corp., Tokyo, Japan) to select 80 human enamel specimens with a hardness between 292.0 and $383.4 \mathrm{kPa}^{\circ} \mathrm{mm}^{-2}$, and 80 human dentin specimens with a hardness between 48.6 and $68.7 \mathrm{kPa} \bullet \mathrm{mm}^{-2}$, for a total of 160 specimens.
Custom-made acrylic palatal appliances were made with 8 cavities $(5 \times 5 \times 4 \mathrm{~mm})$. Enamel and dentin specimens were fixed with wax in the recesses of each individual acrylic palatal appliance. The specimens (enamel and dentin) were randomly divided into rows (at least $1 \mathrm{~cm}$ apart from each other), and the conditions (EROS or EROS + ABRAS) were randomly divided into lines (at least $1 \mathrm{~cm}$ apart) for each volunteer. This split-mouth palatal appliance design has been previously used for testing erosion or erosion+abrasion. ${ }^{4}$

\section{Intraoral phase and treatment}

The Euclea natalensis gel was made from the dried roots of E. natalensis (under controlled parameters), and custom prepared by this research group in the Laboratory of Natural Products at the Universidade Federal de São Carlos - UFSCAR. The gel formulation included 10\% Euclea natalensis extract, Carbopol ${ }^{\circledR}$ 980, methylparaben, EDTA, and sodium hydroxide solution. The participants wore the appliances for $12 \mathrm{~h}$ before starting the erosive wear for each intraoral phase, to allow a salivary pellicle to form..$^{18}$ The gels were then applied in a thin layer using a microbrush, left to remain 5 min and then carefully removed with cotton swabs.

In the intraoral phase, volunteers were instructed to start the erosive wear procedure $6 \mathrm{~h}$ after the gel treatment. During the following 5 days, erosive and abrasive challenges were performed ex vivo 4 times/day (at 8 am, 12 pm, 4 pm, and 8 pm) after the main meals. ${ }^{4}$ In each challenge, the appliance was immersed in a cup containing $150 \mathrm{~mL}$ of a recently opened bottle of cola soft drink ( $\mathrm{pH}$ 2.6; Coca-Cola Co. Spal, Porto Real, Brazil) for 5 min at $25^{\circ} \mathrm{C} .{ }^{4}$ After the erosive wear, the volunteers were instructed to take a small amount of the beverage in their mouth and re-insert the appliance into their mouth. After 30 min of erosive wear, the second two rows were brushed using a soft toothbrush and fluoride dentifrice (Colgate, 1100 ppm F, Colgate-Palmolive Co. ${ }^{\circledR}$, São Paulo, Brazil), for 30 seconds ex vivo ${ }^{4}$.

The volunteers were instructed to wear the appliances continuously for $24 \mathrm{~h}$, except during the main meals (4 times/day), when the appliance had to be stored in wet gauze. Seven days prior to the beginning and throughout the experimental phase, participants 
brushed their teeth with a fluoridated dentifrice. The subjects received written instructions and a schedule, and were extensively trained for all the procedures.

\section{Wear analysis}

The laboratory personnel were blinded to the experimental specimen groups. At the end of the in situ phase, the specimens were remounted on acrylic blocks, and the nail varnish covering the reference surfaces was carefully removed.

Surface profiles of the specimens were obtained with a contact profilometer (Hommel Tester T 1000, Hommelwerke, VS, Schwenningen, Germany). Surface loss was determined as follows: the tape was removed and 5 profiles were recorded at exactly the same sites as those used for the baseline measurement. The profile scans were performed in the center of each specimen at $250 \mu \mathrm{m}$ intervals ${ }^{4,17}$. The specimens were allocated to the treatments by stratified randomization, according to the mean surface microhardness. All the groups presented similar mean microhardness values (about $363 \pm 21 \mathrm{kPa} \cdot \mathrm{mm}^{-2}$ and $68 \pm 7 \mathrm{kPa} \cdot \mathrm{mm}^{-2}$, for enamel and dentin, respectively).

After completion of each experimental phase, the nail varnish was carefully removed from the disc surfaces using an acetone-soaked cotton pellet, prior to analysis of surface wear with a profilometer (Shimadzu, Tokyo, Japan). Five scans were performed on the entire enamel surface. The dentin specimens were kept wet until the analysis, to avoid shrinkage of the collagen fibrils. The values were averaged $(\mu \mathrm{m})$, and the increment value (final values - initial values) was calculated for the enamel and dentin specimens, which were then submitted to statistical analysis (Figure).

\section{Statistical analysis}

The assumptions of equality of variances and normal distribution of errors were analyzed by the Bartlett and Kolmogorov-Smirnov tests, respectively. Since the assumptions were satisfied, the data were analyzed by two-way analysis of variance (ANOVA). Tukey's test was conducted with STATISTICA version 10.0 (Stat-Soft, Tulsa, USA), and used to perform individual comparisons between the groups. The level of significant difference was set at $5 \%$.

\section{Results}

Table 1 shows the mean wear $( \pm \mathrm{SD})$ of the groups in the enamel, and Table 2, in the dentin investigated.

There was no difference between the groups (experimental vs. control) in relation to the enamel $(p>0.05)$. However, there was one between them for erosive and abrasive challenges in the dentin $(p<0.05)$. The Euclea natalensis gel caused less wear in the enamel for the erosive $(12.86 \pm 1.75 \mu \mathrm{m})$ or erosive+abrasion $(12.13 \pm 2.12 \mu \mathrm{m})$ challenge in the experimental group, compared with the control group $(14.12 \pm 7.66 \mu \mathrm{m}$ and $16.29 \pm 10.72 \mu \mathrm{m}$, respectively, $p>0.05)$. The best preventive effect was observed for the dentin under the experimental conditions of erosive $(5.81 \pm 1.00 \mu \mathrm{m})$ or erosive+abrasion $(6.16 \pm 1.00 \mu \mathrm{m})$ challenges, which yielded a significantly lower mean wear than that observed for the control group $(\mathrm{p}<0.05)$.

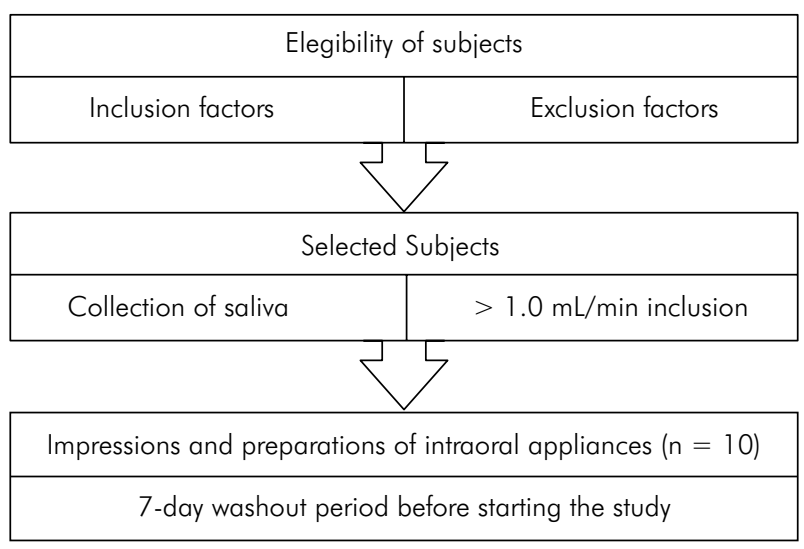

$12 \mathrm{~h}$ before study started, the volunteers wore the appliance

$1^{\text {st }}$ phase of study ( $n=5$, subjects $1-5$, gel $\mathrm{n}=5$, subjects 6-10, without gel)

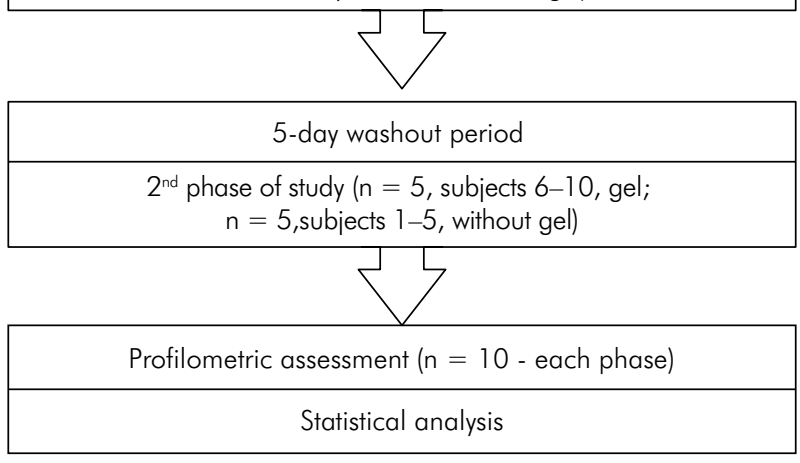

Figure. Flowchart of the study 
Table 1. Wear $(\mu \mathrm{m})$ of the enamel (mean \pm SD), with or without application of the gel, under two experimental conditions.

\begin{tabular}{lcc}
\hline Condition & Euclea natalensis & Control \\
\hline Erosion & $12.86 \pm 1.75$ & $14.12 \pm 7.66$ \\
Erosion + Abrasion & $12.13 \pm 2.12$ & $16.29 \pm 10.72$ \\
\hline
\end{tabular}

SD: standard difference. No significant difference was found $(p>0.05)$.

Table 2. Wear $(\mu \mathrm{m})$ of dentin (mean \pm SD), with or without application of the gel, under two experimental conditions.

\begin{tabular}{lcc}
\hline Condition & Euclea natalensis & Control \\
\hline Erosion & $5.81 \pm 1.00^{\mathrm{Aa}}$ & $13.85 \pm 9.60^{\mathrm{Ab}}$ \\
Erosion + Abrasion & $6.16 \pm 1.00^{\mathrm{Aa}}$ & $13.77 \pm 7.73^{\mathrm{Ab}}$ \\
\hline
\end{tabular}

SD: standard difference; $n=10$. Different lowercase letters in the same line indicate significant differences between the groups $(p=0.001)$; Equal capital letters in the same column indicate no significant difference between the conditions $(p>0.05)$.

\section{Discussion}

In situ models are commonly adopted for assessing erosion and abrasion involving the use of oral devices. ${ }^{19}$ In the present in situ study, there was no significant difference between the experimental group using Euclea natalensis gel and the control group, in relation to the enamel ( $p>0.05)$, and a significant difference in relation to dentin erosive wear $(p<0.05)$, which may be attributed to the difference in enamel and dentin composition, and which may interfere in the erosive process. In enamel, the initial stage of erosion is characterized by a softening of the surface, due in part to the demineralization of the surface. On the other hand, dentin erosion is first apparent at the interface between the inter- and peritubular dentin, and greater exposure time causes hollowing and funneling of the tubules. Ultimately, the peritubular dentin is completely dissolved. ${ }^{20}$

Saliva performs specific functions to protect the tooth structure, by buffering the capacity of calcium, phosphate and fluoride supersaturation. ${ }^{21}$ The protective functions of saliva include dealing with the challenges of erosion: thinning and clearing of erosive substances in the oral cavity; inducing neutralization of acid buffering by bicarbonate ions; providing calcium, phosphate and fluoride; possibly promoting needed remineralization; and maintaining a supersaturated state on the tooth surface, since calcium and phosphate are present in saliva. Assessment of salivary flow required that one of the criteria for the volunteers to be included in this study was having normal salivary flow. Low salivary flow may contribute to the symptoms of erosion, since saliva and its components protect the teeth by neutralizing acidity. ${ }^{16}$

The salivary pellicle formed may serve as a diffusion barrier or semi-permeable membrane, preventing direct contact between the acids and the tooth surface, thereby preventing demineralization. ${ }^{22,23}$ Accordingly, it seemed to have some effect on the enamel, by reducing the acid challenge in both groups. Future studies could show the differences between the periods of applied gel formation and the benefits gained.

A greater loss of enamel substance was observed in the control group, when erosion was associated with abrasion, although it was not statistically significant between the groups. This reinforces the hypothesis that the enamel brushing performed after $30 \mathrm{~min}$ should have been postponed for 1 hour, since there was a greater loss of erosion associated with abrasion. This is in agreement with the literature ${ }^{24,25}$, which has proposed that oral hygiene (brushing) should be performed after the intake of food to prevent against the salivary buffering of the acidic $\mathrm{pH}$ of food, considering that the proximity between the time of acidic food intake and regular tooth brushing are risk factors for dental erosion. When oral hygiene (brushing) is performed immediately after meals, one's saliva cannot rebalance the $\mathrm{pH}$, which remains acidic, and which, together with the mechanical force performed during brushing, leads to a synergistic effect. . $^{2425}$

Studies have shown that dentin demineralization occurs in the peritubular dentin ${ }^{26,27}-18-20 \%$ contains organic material, and $90 \%$ is type I collagen. The presence of a collagen-rich dentin surface decreases the diffusion of acids in the tissue, and further exhibits buffering properties, which minimize dental erosion. The organic matrix of dentin can be degraded both mechanically and chemically, which may contribute to the further progression of dentin wear. Chemically, the organic matrix of dentin can be degraded by MMPs (mainly MMP 8, 9 and 2) that cause the breakdown of 
virtually all extracellular matrix molecules, including native and denatured collagen. ${ }^{15}$

An in situ study evaluated the effect of a solution containing $0.61 \%$ green tea extract, versus none, in reducing dentin wear by erosion followed by abrasion. The result demonstrated that the solution containing green tea showed a reduction in wear, compared with the control group, for both conditions. The authors concluded that the presence of polyphenols present in green tea may have an inhibitory effect on the MMPs present in the dentin matrix..$^{10}$ A study using histochemical analysis revealed the presence of naphthoquinones and polyphenols (such as flavonoids and tannins) in the root of the Euclea natalensis. ${ }^{12,28,29}$ According to the literature presented, ${ }^{28,29}$ the therapeutic effect of Euclea natalensis extract could be attributed to matrix metalloproteinases inhibition in the dentin. This may be justified, because the hardness analysis showed that there was a higher loss of hardness in the Euclea natalensis group, which, in turn, indicates the possibility of the collagen fiber structure having some flexibility.

Condensed tannins (CT) or proanthocyanidin units consist of flavanol: flavan3-ols (catechins) and flavan3,4-diols (leucoanthocyanins), may contain 20 to 50 flavonoid units, have a complex structure, and are resistant to hydrolysis, but may be soluble in

\section{References}

1. Bawa S. The role of the consumption of beverages in the obesity epidemic. J R Soc Promot Health. 2005;125(3):124-8. doi:10.1177/146642400512500316

2. Touyz L, Mehio A. Dental ravages from acidulated soft drinks. J Aesthet Implant Dent. 2006;8(3):20-33.

3. Attin T, Knöfel S, Buchalla W, Tütüncü R. In situ evaluation of different remineralization periods to decrease brushing abrasion of demineralized enamel. Caries Res. 2001;35(3):216-22. doi:10.1159/000047459

4. Sales-Peres SHC, Pessan JP, Buzalaf MA. Effect of an iron mouthrinse on enamel and dentine erosion subjected or not to abrasion: an in situ/ ex vivo study. Arch Oral Biol. 2007;52(2):128-32. doi:10.1016/j.archoralbio.2006.08.010

5. Wiegand A, Attin T. Influence of fluoride on the prevention of erosive lesions: a review. Oral Health Prev Dent. 2003;1(4):245-53.

6. Magalhães AC, Rios D, Delbem AC, Buzalaf MA, Machado MA. Influence of fluoride dentifrice on brushing abrasion aqueous organic solvents, depending on their structure. In addition, they can precipitate proteins from the cells, and thus form a protective layer, ${ }^{30}$ which could be one of the reasons for the beneficial effects of Euclea natalensis.

Furthermore, several studies have shown that the polyphenolic compounds present in Euclea natalensis may have inhibited the adhesion of $S$. mutans to hydroxyapatite, while others discuss their effect in promoting enamel remineralization. ${ }^{28,29}$ Euclea natalensis extract alone may be an alternative product to protect oral health and prevent dental caries, ${ }^{13}$ tooth wear and dentinal sensitivity. ${ }^{31}$ For this reason, the effect of the chemical properties of Euclea natalensis as modifying factors for dental erosion should be explored in future investigations.

\section{Conclusion}

Euclea natalensis may play a role in the prevention of dentin loss under erosive and abrasive conditions. A clinical trial is required to confirm these promising results in a clinical situation.

\section{Acknowledge}

Supported by Conselho Nacional de Desenvolvimento Científico e Tecnológico - CNPq and Fundação de Amparo à Pesquisa do Estado de São Paulo - FAPESP - 2010/09951-0.

of eroded human enamel: an in situ/ex vivo study. Caries Res. 2007;41(1):77-9. doi:10.1159/000096110

7. Huysmans MC, Jager DH, Ruben JL, Unk DE, Klijn $\mathrm{CP}$, Vieira AM. Reduction of erosive wear in situ by stannous fluoride-containing toothpaste. Caries Res. 2011;45(6):518-23. doi:10.1159/000331391

8. Sales-Peres SHC, Carvalho FN, Marsicano JA, Mattos MC, Pereira JC, Forim MR, et al. Effect of propolis gel on the in vitro reduction of dentin permeability. J Appl Oral Sci. 2011;19(4):318-23. doi:10.1590/S1678-77572011005000004

9. Sales-Peres AC, Marsicano JA, Garcia RP, Forim MR, Silva MFGF, Sales-Peres SHC. Effect of natural gel product on bovine dentin erosion in vitro. J Appl Oral Sci. 2013;21(6):597-600. doi:10.1590/1679-775720130242

10. Magalhães AC, Wiegand A, Rios D, Hannas A, Attin T, Buzalaf MA. Chlorhexidine and green tea extract reduce dentin erosion and abrasion in situ. J Dent. 2009;37(12):994-8. doi:10.1016/j.jdent.2009.08.007 
11. Taheri JB, Azimi S, Rafieian N, Zanjani HA. Herbs in dentistry. Int Dent J. 2011;61(6):287-96. doi:10.1111/j.1875-595X.2011.00064.x

12. Homer KA, Manji F, Beighton D. Inhibition of protease activities of periodontopathic bacteria by extracts of plants used in Kenya as chewing sticks (mswaki). Arch Oral Biol. 1990;35(6):421-4. doi:10.1016/0003-9969(90)90203-M

13. Stander I, Van Wyk CW. Toothbrushing with the root of Euclea natalensis. J Biol Buccale. 1991;19(2):167-72.

14. More G, Tshikalange TE, Lall N, Botha F, Meyer JJ. Antimicrobial activity of medicinal plants against oral microorganisms. J Ethnopharmacol. 2008;119(3):473-7. doi:10.1016/j.jep.2008.07.001.

15. Kato MT, Leite AL, Hannas AR, Buzalaf MA. Gels containing MMP inhibitors prevent dental erosion in situ. J Dent Res. 2010;89(5):468-72. doi:10.1177/0022034510363248

16. Scaramucci T, Sobral MA, Eckert GJ, Zero DT, Hara AT. In situ evaluation of the erosive potential of orange juice modified by food additives. Caries Res. 2012;46(1):55-61. doi:10.1159/000335572

17. Honório HM, Rios D, Santos CF, Magalhães AC, Delbem AC, Buzalaf MA, et al. Cross-sectional microhardness of human enamel subjected to erosive, cariogenic or combined erosive/cariogenic challenges. Caries Res. 2010;44(1):29-32. doi:10.1159/000275571

18. Hara AT, Ando M, González-Cabezas C, Cury JA, Serra MC, Zero DT. Protective effect of the dental pellicle against erosive challenges in situ. J Dent Res. 2006;85(7):612-6. doi:10.1177/154405910608500706

19. Wiegand A, Attin T. Design of erosion/abrasion studies -insights and rational concepts. Caries Res. 2011;45(Suppl 1):53-9. doi:10.1159/000325946

20. Sales-Peres SHC, Reinato JVD, Sales-Peres AC, Marsicano JA. Effect of iron gel on dentin permeability. Braz Dent J. 2011;22(3):198-202. doi:10.1590/S0103-64402011000300004

21. Lussi A, Jaeggi T, Zero D. The role of diet in the aetiology of dental erosion. Caries Res. 2004;38(Suppl 1):34-44. doi:10.1159/000074360
22. Amaechi BT, Higham SM, Edgar WM, Milosevic A. Thickness of acquired salivary pellicle as a determinant of the sites of dental erosion. J Dent Res. 1999;78(12):1821-8. doi:10.1177/00220345990780120901

23. Hannig M, Balz M. Influence of in vivo formed salivary pellicle on enamel erosion. Caries Res. 1999;33(5):372-9. doi:10.1159/000016536

24. Bartlett DW. The role of erosion in tooth wear: aetiology, prevention and management. Int Dent J. 2005;55(Suppl 4):277-84. doi:10.1111/j.1875-595X.2005.tb00065.x

25. Resende VLS, Castilho LS, Faria CVCM, Teixeira GS, Lima ICP, Campos MCBM, et al. Dental erosion or perimolysis: the importance of health team-work. Arch Odontol. 2005;41(2):32-8.

26. Kinney JH, Balooch M, Haupt DL Jr, Marshall SJ, Marshall GW Jr. Mineral distribution and dimensional changes in human dentin during demineralization. J Dent Res. 1995;74(5):1179-84. doi:10.1177/00220345950740050601

27. Ganss C, Klimek J, Schäffer U, Spall T. Effectiveness of two fluoridation measures on erosion progression in human enamel and dentine in vitro. Caries Res. 2001;35(5):325-30. doi:10.1159/000047470

28. Li YB, Lin ZQ, Zhang ZJ, Wang MW, Zhang H, Zhang QW, et al. Protective, antioxidative and antiapoptotic effects of 2-methoxy-6-acetyl-7-methyljuglone from Polygonum cuspidatum in PC12 cells. Planta Med. 2011;77(4):354-61. doi:10.1055/s-0030-1250385

29. Petti S, Scully C. Polyphenols, oral health and disease: a review. J Dent. 2009;37(6):413-23. doi:10.1016/j.jdent.2009.02.003

30. Haslam E. Natural polyphenols (vegetable tannins) as drugs: possible modes of action. J Nat Prod. 1996;59(2):205-15. doi:10.1021/np960040+

31. Sales-Peres SHC, Brianezzi LFR, Marsicano JA, Forim MR, Silva MFGF, Sales-Peres A. Evaluation of an experimental gel containing euclea natalensis: an in vitro study. Evid Based Complement Alternat Med. 2012;2012:184346. doi: 10.1155/2012/184346. 